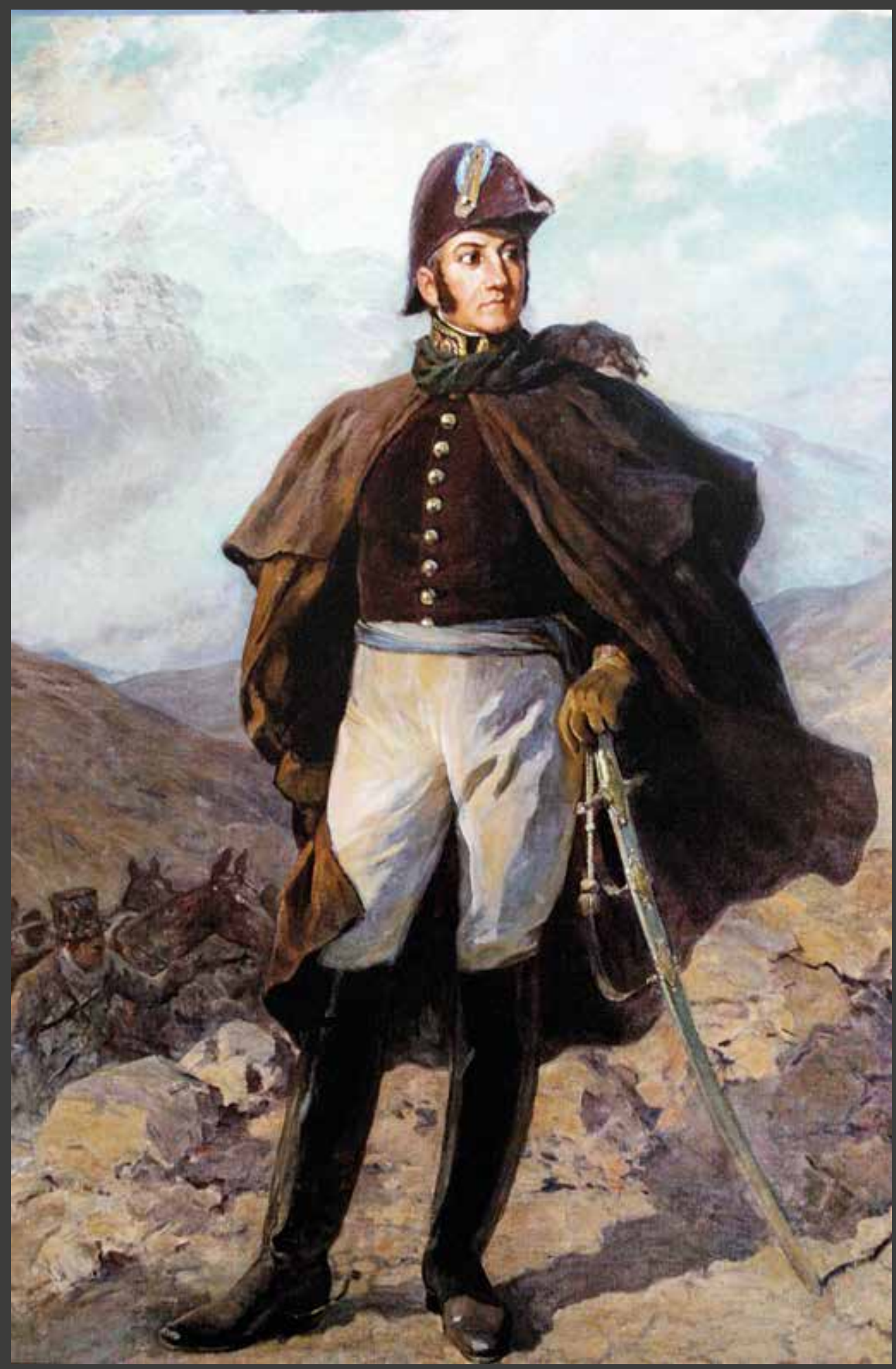

Fig.1: Daniel Hernández, José de San Martín, libertador del Perú (1919), óleo sobre lienzo, Hemiciclo principal, Congreso del Perú. 


\section{Recreando imaginarios: Del general José de San Martín a Augusto B. Leguía}

Fernando Villegas Torres ${ }^{1}$

Pontificia Universidad Católica de Perú

El presente ensayo aborda la iconografía de San Martín representada por pintores y escultores peruanos y extranjeros. Vemos como los artistas reconocieron en San Martin el haber sido quien proclamó la independencia del Perú. Este aspecto de orador fue la cualidad que lo distinguió y que fue apropiada por Leguía cuando este se asoció con la figura de San Martin y se proclamó como el fundador de la Patria nueva.

\section{Iconografía de San Martin / Augusto B. Leguía /Daniel Hernández/ arte y política/Carlos Baca Flor/pintura y escultura peruana en el oncenio}

This essay seeks to investigate the iconography of José de San Martín (1778-1850) as shown in his portrayal by Peruvian and foreign painters and sculptors. We see how these artists acknowledged San Martín as the one who proclaimed the independence of Peru. This rhetorical aspect was the key element that distinguished him and this same element would later be appropriated by Augusto B. Leguía (1863-1932), when the latter one associated himself with the figure of San Martín and proclaimed himself the founder of the "Patria Nueva".

Iconography of José de San Martín / Augusto B. Leguía / Daniel Hernández / art and politics / Carlos Baca Flor / Peruvian painting and sculpture during the Oncenio

(1919-1930)

¿Por qué todos nosotros, especialistas, yo menos que ustedes,
puede interesarnos y apasionarnos tanto la independencia?
Para mí, por un hecho fundamental: la sentimos como una
frustración que todavía es una responsabilidad nuestra

(Macera, 1971:18).

Una de las figuras de la independencia americana que fue rescatada durante la celebración de los Centenarios fue José de San Martín. En 1919, el recién nombrado director de la Escuela de Bellas Artes de Lima, el pintor peruano Daniel Hernández, realizó los Retratos del general San Martín (Fig.1) y de Simón Bolívar. En el primero, el personaje aparecía con bicornio y de cuerpo entero, en actitud observante. En cuanto al rostro, buscó darle veracidad al tomar como modelo el retrato histórico que fue autorizado por el propio San Martín, cuando el Mariscal Miller publicó sus memorias (1829) ${ }^{2}$.

1 El presente artículo pertenece a una parte del noveno capítulo de mi tesis doctoral en Historia del Arte. Ver: (Villegas, 2013:396-412). Además, fue presentado como ponencia en el V Simposio de Historia del Arte Peruano "Enrique Iturriaga Romero", Facultad de Letras y Ciencias Humanas, UNMSM, 28 de noviembre de 2014.

2 La carta de autorización de la imagen escrita por San Martín fue reproducida en Mundial en su número extraordinario que conmemoraba el Centenario de la Independencia. 


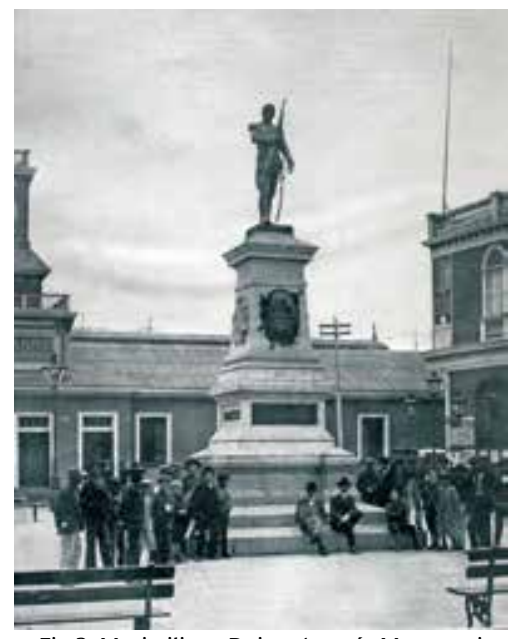

Fig.2: Maximiliano Doig y Agustín Marazzani Visconti, Monumento a San Martín (Prisma, Lima, N²7, 1 XII 1906, p.4).
El pintor había representado a dos personalidades destacadas de la gesta independentista, que de alguna forma serían vistos de manera desigual en el imaginario peruano, que prefería a San Martín sobre Bolívar. No sorprende que el crítico de arte y pintor Teófilo Castillo, en sus escritos en Variedades, responsabilizara a Bolívar de desmembrar al Perú y crear Bolivia, o que un artículo de Mundial, tiempo después, diera cuenta de las múltiples calles, avenidas y monumentos realizados en Lima que llevaban el nombre de San Martín (Ego, 1929). Además, la Nación tenía una deuda de gratitud con el general argentino, que vino a las costas peruanas a proclamar la independencia. Éste, a diferencia de Bolívar que poseía una escultura ecuestre, la primera en erigirse en Lima en 1856, no tenía una escultura representativa en un punto central de la ciudad.

A cien años de la independencia peruana, el general José de San Martín fue el héroe más recordado. Tal vez esto motivó que la delegación venezolana no participara en los agasajos que se realizaron en la ciudad (Basadre, 1968:78). Como es sabido, el principal evento de la celebración del Centenario peruano fue la inauguración del Monumento a San Martín (1921)3.

El poeta Luis Benjamín Cisneros publicó San Martín en la Revista de Lima. En él hacía mención que, tras la muerte del héroe en Francia (1849), el gobierno peruano había decidido, por medio de un decreto, realizar un monumento en una plaza pública de la capital, pero el lugar no se había concretado. La erección del primer monumento a la memoria de San Martín, tuvo que esperar los inicios del siglo XX y no fue precisamente en la capital, sino en el puerto del Callao, por erogaciones voluntarias de la comuna chalaca. El monumento se inauguró el 30 de julio de 1903 y contó con la participación de Maximiliano Doig, responsable del trazado y la ejecución, el escultor italiano Agustín Marazzani Visconti (Fig.2) y el asesoramiento del escultor peruano Ricardo Gaspar Suárez. De esta manera, el Callao "se convirtió en el primer pueblo del Perú al que corresponde el honroso título de haber erigido la primera estatua en el suelo que libertó el gran patriota argentino" (Anónimo, 1901:1). Inicialmente se ubicó en la Plaza Gálvez hasta que fue trasladado a un emplazamiento situado entre la avenida Buenos Aires y Chucuito (1935).

El segundo monumento levantado a la memoria del héroe, fue el obelisco del escultor italiano Piero Nicole, donado por el coronel argentino Lucas Pérez Roca. La escultura fue ejecutada por el joven escultor español Lorenzo Rosellót y se inauguró el 30 de agosto de 1906 en el Parque de la Exposición (Fig.3). Sobre la obra, Federico Larrañaga, uno de los principales críticos de arte de la época, señaló:

Una medianísima obra de cementerio, una tumba con ínfulas monumentales, que ni entusiasma, ni glorifica, y resulta una lección de cartilla de escuela para la admiración de las posteridades (...) Su aspecto lapidario, su falta de ligereza,

3 Las propuestas de erigir un monumento a San Martín se dieron desde el siglo XIX (Ver: Monteverde, 2014).

4 Lorenzo Roselló: escultor español de origen mallorquín, falleció en 1901 a los 34 años. Residió en Lima, donde realizó la Escultura de San Martín tras ganar un concurso. El escultor mallorquín había presentado El descubrimiento de América en la sección peruana de la Exposición de Madrid de 1893, donde obtuvo el primer premio. Desolación fue premiada en París, donde también obtuvo por el grupo Vers le bon chemin la medalla de plata. En Barcelona ganó medalla de plata por Hornero Balear. En el Salón de Sesiones de Palma de Mallorca se conservan los Bustos de Ramon Llull y de Sagrera (Anónimo, 1901:5). 


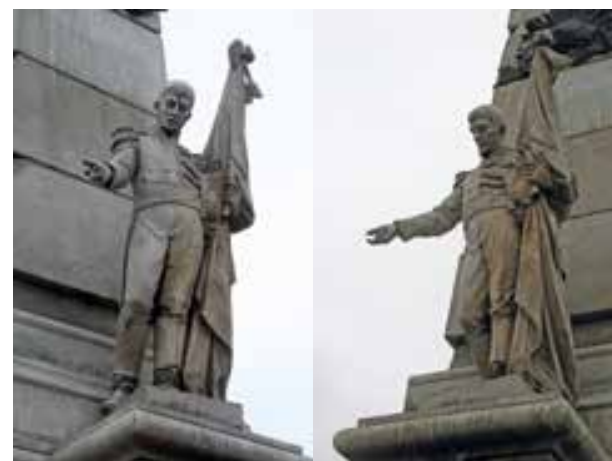

Fig.3: Piero Nicole. Monumento a San Martín (Prisma, Lima, $\mathrm{N}^{\circ} 28,16$ XII 1906, p.21)

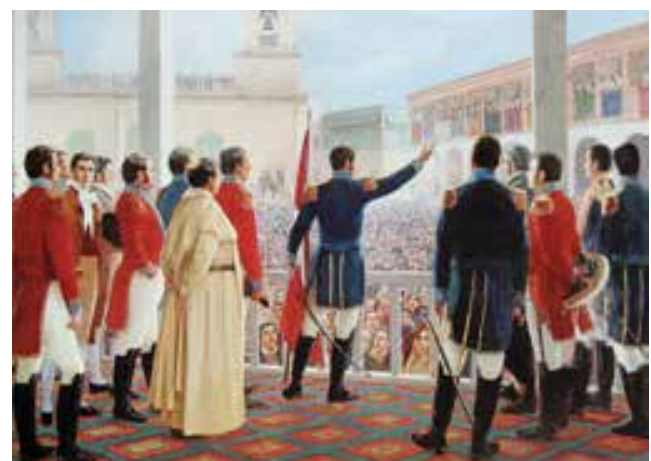

Fig.4: Juan Oswaldo Lepiani. La proclamación de la independencia (1903), óleo sobre lienzo, 2,79 x 4,03 cm, Museo Nacional de Arqueología, Antropología e Historia del Perú

su forma vulgar de pirámide, sus múltiples desproporciones, su mísera ornamental y sus incoherencias artísticas, lo hacen banal, indiferente, triste, indigno de la idea que pretende representar, mezquinamente encaramado sobre su base estrecha, de monótonos lineamientos. Un obelisco desfigurado y de escasa elevación, un ángel alado de Iglesia, subido en los aires, un ángel de aquellos que suelen custodiar la entrada de las tumbas (Larrañaga, 1906b:1838).

Al parecer, la opinión adversa de Larrañaga tuvo aceptación ya que cuando el monumento fue trasladado a la avenida Sáenz Peña en Barranco en $1926^{5}$, por iniciativa del alcalde distrital (Anónimo, 1926), la escultura del ángel que remataba el obelisco había sido retirada. (Gamarra, 1996:60-61).

Ambas esculturas enfatizaban el ideal patriota de San Martín al colocarlo junto a la bandera peruana que rodea con su brazo. Tal vez, incluso su postura tenía como objetivo realzar la propia proclamación de la independencia, al levantar su mano derecha y dirigir su mirada al público. Con esto seguía el modelo del pintor peruano Juan Oswaldo Lepiani, que tres años antes había mandado desde Roma, donde residía como pensionado, su cuadro $L a$ proclamación de la independencia (1903) (Fig.4). En la pintura, el general estaba representado de espaldas, sujetando la bandera peruana con la mano izquierda y levantando la derecha hacia un público claramente identificable como limeño, por la presencia de la tapada, imagen costumbrista que aparece en primer plano ${ }^{6}$. Entre la multitud, preferentemente

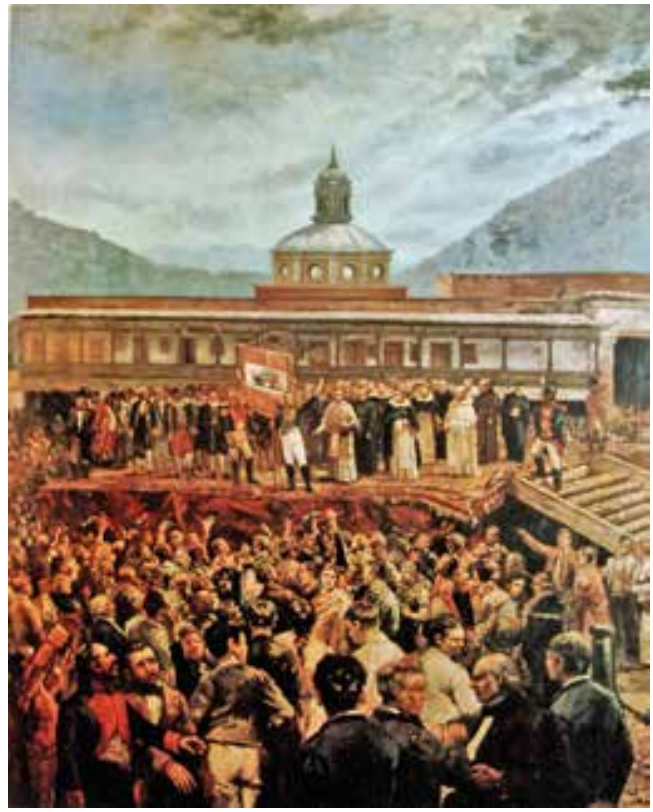

Fig.5 : Ignacio Merino, Proclamación de la Independencia, (c.1850), óleo sobre lienzo, 100 x $80 \mathrm{~cm}$, Colección privada.

5 En la placa actual del monumento dice que fue inaugurado el 28 de julio de 1924, siendo presidente Augusto B. Leguía, alcalde de Lima Pedro J. Rada y Gamio y alcalde de Barranco Enrique de Las Casas.

6 La importancia de la imagen de Lepiani ha sido resaltada por Gonzalo Portocarrero (2015: 30) como: "la imagen 'clásica', oficial y hegemónica de la proclamación de la independencia. Ella se reitera en los textos y láminas escolares, de manera que es parte del archivo o cultura visual de (casi) todos los peruanos". 
criolla, también destaca la figura de un afrodescendiente que escucha atentamente las palabras de libertad dirigidas al pueblo peruano. Este modelo iconográfico en torno a la representación de San Martín, aparece por primera vez en Proclamación de la Independencia del pintor académico Ignacio Merino (Fig.5).

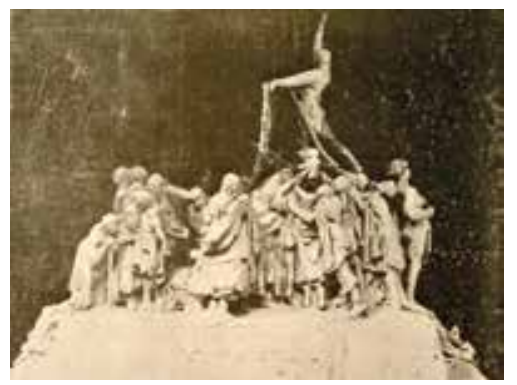

Fig.6: Calos Baca Flor. Liberté, égalité, fraternité (Prisma, Lima, №13, 1 V 1906, p.32).

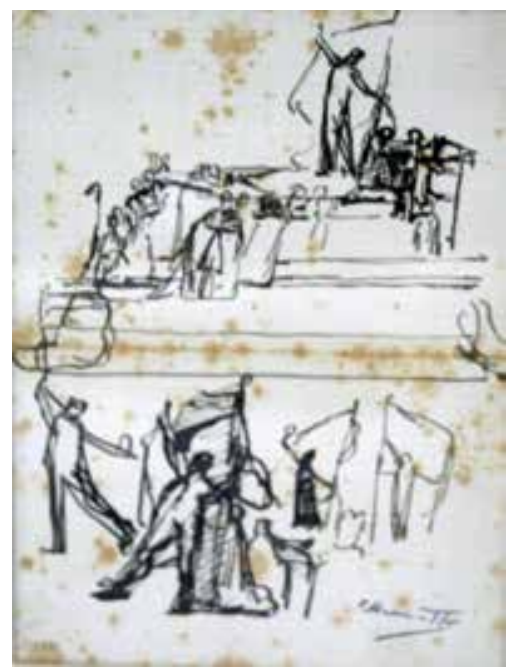

Fig.7: Carlos Baca Flor. Dos estudios para el monumento a San Martín (c.1904), tinta sobre papel, 45 x 35,7 cm, Museu de Terrassa (MT).

\section{El Monumento a San Martín}

En 1906, el gobierno peruano convocó a un concurso para mantener viva la memoria del general San Martín. Uno de los proyectos destacaba por su calidad artística, se trataba del proyecto Liberté, egalité, fraternité, presentado por el pintor peruano Carlos Baca Flor (Fig.6) que mantenía la representación de San Martín declamando la independencia. El Museu de Terrassa conserva tres dibujos a pluma del monumento presentado por Baca Flor ${ }^{7}$ (Fig.6 y 7). En uno de estos bocetos el pintor ensayó el movimiento que quería darle a la figura de San Martín a través de la posición de los pies del personaje, que fue repetida en las otras dos figuras del prócer. En los otros dos bocetos representó el monumento de perfil; en ellos destaca la figura de San Martín cogiendo la bandera sobre un grupo de gente apenas esbozado. El resultado final del proyecto escultórico que fue llevado a concurso, enfatiza la figura de San Martín sin la bandera, levantando el brazo derecho con el que señala el cielo y con la mano izquierda rompe las cadenas de la opresión. La posición de los pies respetó la idea de movimiento del boceto antes mencionado.

Federico Larrañaga, en esta ocasión, publicó sus comentarios favorables en Prisma y Actualidades.

¿Quién no siente ante este simple bosquejo de lo que será la gran obra, erguirse en sí el sentimiento patriótico, ante ese arranque de grandeza escultural y de inspiración histórica? Bien meditado, ejecutando con fervor, labrando un ideal, ha realizado para todo espíritu culto, la más inmensa contribución de patriotismo y dado al mundo, una primicia de arte trascendental (...) el San Martín de Baca Flor, más que heroico, más que humano, más que Gran Libertador y argentino, es ídolo, un ideal que se mece en el girón de una capa, triunfal, rítmicamente inseparable, hecha así para impulsar la acción, vibrante, ondulando hiperbólicamente, encarrujada y esponjosa como una serpiente, azotada por todos los vientos é iracunda, en múltiples curvas; no arropando al militar, ni al espadachín, ni al Generalísimo, como la vulgaridad estúpida lo interpreta, sino al Apóstol, al Mesías popular, que como tal, debe llevar algo de fantástico, de lo infinito de lo ultraterrestre ${ }^{8}$.

Un grupo de intelectuales y artistas se reunió en la sede de Actualidades para apoyar el proyecto presentado por Baca Flor como el más idóneo para obtener el triunfo del concurso

7 Las piezas están consignadas con los códigos 13482 (2) y 13420 (1).

8 Larrañaga, 1906a: 443-445. 
(Anónimo, 1906). Ya en otro artículo se resaltó que por sus características modernistas estaba lejos del gusto realista de la época, además de su desconcertante actualidad al representar a los tipos peruanos contemporáneos (Villegas, 2010:218).

A pesar de ello, el concurso se declaró desierto y el gobierno peruano comisionó su realización al escultor español Mariano Benlliure y Gil (Larrañaga, 1906:1337) ${ }^{9}$. Ya en 1916, se conoce que el cónsul del Perú en Barcelona, José de la Colina, no tenía noticias de las medidas y el peso de los setenta cajones que contenían el Monumento a San Martín, requisito indispensable que le pedían las compañías navieras para efectuar su traslado a Lima ${ }^{10}$. Se solicitó a la Compañía Trasatlántica Española un presupuesto, pero ésta no hacía escala en Alicante. Las cajas debían estar en Valencia, Barcelona, Málaga o Cádiz. De la Colina sugería que las piezas fueran llevadas de Alicante a Vigo, donde la Pacific Steam Navigation Company las podía trasladar al Callao (De la Colina, 1916a). En ese mismo año un artículo firmado con el seudónimo de El Corresponsal, publicado en La Nación de Buenos Aires, informaba que todavía no se había decidido dónde colocar el Monumento a San Martín en Lima. Se barajaban tres posibles lugares: la Plaza Mayor de Lima donde San Martín pronunció su discurso, la Plaza de Zela o un parque que se construiría frente a la Plaza de la Exposición ( $E l$ Corresponsal, 1916).

El proyecto de Benlliure representaba la figura de San Martín a caballo a su paso por los Andes, camino a proclamar la independencia peruana. El héroe aparecía en tránsito donde la escultura perdía toda relación con su entorno (Fig.8). Se enfatizó la larga marcha emprendida por el personaje desde Argentina, donde tuvo que cruzar los Andes para liberar

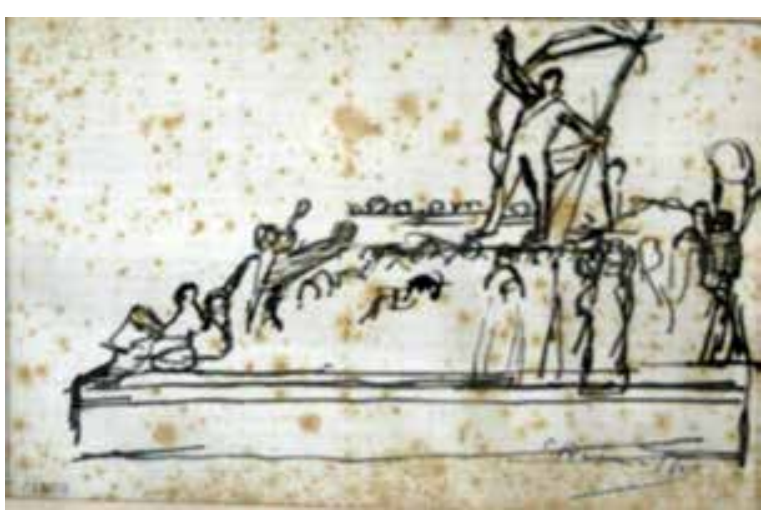

Fig.8: Carlos Baca Flor. Un estudio para el monumento a San Martín (c.1904), tinta sobre papel, 13,5 x $20 \mathrm{~cm}$, Museu de Terrassa (MT).

a los pueblos de Chile y el Perú. En palabras de Benjamín Cisneros: "La figura de San Martín atravesando los Andes es una figura colosal: lo demás es una epopeya” (Cisneros, 1921). Es decir, no importaba a quiénes liberó, sino únicamente la acción de liberarlos. La heroicidad de San Martín se hacía evidente por su victoria sobre la geografía y el cumplimiento de su misión. A esto se añade el carácter cosmopolita e internacional de la pieza, un aspecto que fue criticado por la prensa de entonces, ya que formalmente no se establecía una relación directa entre el héroe y la proclamación de la independencia peruana, principal evento que se celebraba en las fiestas centenarias.

Por otro lado, la prensa peruana criticó el movimiento antinatural del caballo. La estatua ecuestre, la segunda que se realizó en Lima, estaba acompañada en la base del monumento por la representación alegórica de la conquista. Era una figura femenina con ropaje griego que llevaba el yelmo usado por los soldados españoles durante la conquista de los incas.

9 Se conoce que Benlliure fue escogido por el gobierno peruano de manera arbitraria y sin concurso en 1907. Antes habían solicitado a los escultores españoles Miguel Blay, Agustín Querol y Mariano Benlliure realizar el proyecto y, ante la negativa de estos, al enterarse de la participación de los otros escultores el gobierno peruano decidió designar al escultor valenciano para realizar el proyecto. Hacia 1908, ya había mandado el proyecto: un modelo a escala en yeso, varias fotografías y un texto descriptivo. (Ver: Mejía, 2013: 50).

10 Este problema persistió durante los meses de julio y septiembre del mismo año, como se sabe por cartas del cónsul del Perú en Barcelona (De la Colina, 1916b, 1916c). 
Sobre el casco, el artista colocó una inusual representación de la llama, camélido andino ${ }^{11}$. El encargado de la disposición del monumento fue un discípulo de Benlliure, el escultor español Gregorio Domingo ${ }^{12}$.

Teniendo como invitados en las fiestas del Centenario al mariscal Andrés Avelino Cáceres, héroe peruano vivo de la Guerra del Pacífico, y al general francés Charles Mangin, héroe de la Batalla de Verdún ${ }^{13}$, que había tenido lugar durante el reciente conflicto mundial, se inauguró el Monumento a San Martín el 27 de julio de 1921. A nuestro juicio, fue en esos años que Leguía, a través de su pintor Hernández, vinculó su imagen con la de San Martín. A continuación se explicará cómo lo consiguió sirviéndose del arte.

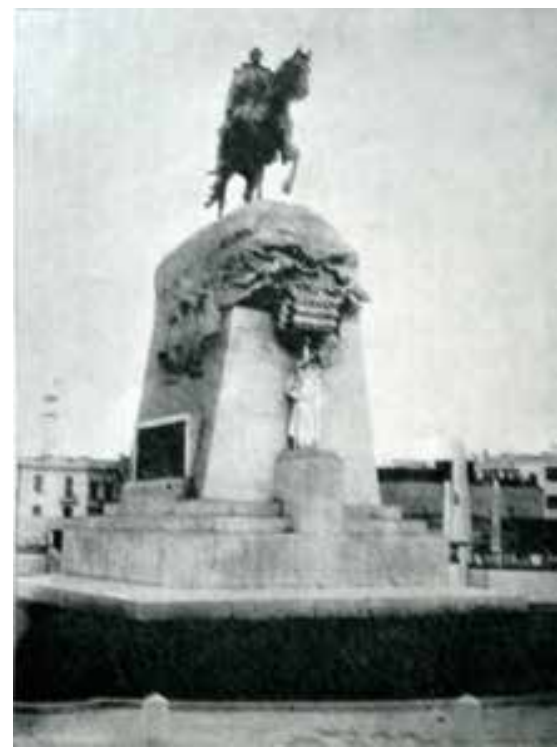

Fig.9: Mariano Benlliure. Monumento a San Martín (Variedades, Lima, №1116, 26 VII 1929).
De San Martín a Leguía: del prócer de la independencia al fundador de la patria nueva Con el derrocamiento de Augusto B. Leguía, en los años treinta, un grupo enardecido se dirigió a la Alameda de los Descalzos para destruir el Arco del Triunfo dedicado a los próceres de la independencia, especialmente al general José de San Martín, cuya primera piedra se había colocado en 1921, por iniciativa del alcalde distrital. Pero, ¿por qué un monumento asociado a la figura de San Martín era destruido por la masa popular que había rechazado el régimen autoritario y dictatorial de Leguía?, ¿acaso el arco, que tuvo por finalidad recordar a San Martín, de alguna manera se asoció a Leguía? A continuación, para desentrañar estas interrogantes, comentaremos las referencias directas recogidas en la gráfica, la pintura y la escultura que reconocen una iconografía particular de representar a San Martín para finalmente ver como luego se vincula al creador de la patria nueva.

La figura de San Martín se había convertido en la principal candidata para ser homenajeada durante la celebración del primer Centenario por haber proclamado la independencia. Leguía, que necesitaba la legitimación de su poder político, aprovechó hábilmente la figura del prócer para asociarse a ella. Durante los años previos a la celebración del primer Centenario, hubo una intensa campaña de represión que se tradujo en la deportación de sus adversarios políticos, la censura a la prensa y la clausura de la Universidad. Las libertades democráticas fueron vulneradas y la supuesta madurez política del país se puso en

11 Una nueva aproximación a la representación del camélido en el yelmo la da Monteverde cuando se refiere a la presencia de la cornucopia y unas hojas de ¿árbol de la quina?, con ello el autor hace una alusión a las tres riquezas naturales representadas en el escudo nacional peruano. (Ver: Monteverde, 2014).

12 Gregorio Domingo y Gutiérrez: natural de Madrid, discípulo de Agustín Querol, premiado con mención honorífica en la Exposición Nacional de Bellas Artes de 1899. Vive en 1901 en Santa Engracia, 104. Presentó a la Exposición Nacional de Bellas Artes de 1901 las siguientes obras: 1267 La Fuerza (figura en yeso) alto $1,85 \times$ ancho 1,08 y 1268 Busto (retrato en barro crudo) alto 0,50 x 0,35 (Anónimo,1901:169). Exhibió en la Exposición Nacional de Bellas Artes de 1908 La primera salida (grupo en yeso), 0,90 x 0,78 (Anónimo, 1908:73). En 1910 cambió su domicilio a Santa Engracia 94. Fue discípulo de Don Mariano Benlliure. Mostró en la Exposición Nacional de Bellas Artes de 1910 Medallón retrato (yeso), 0,40 x 0,40 (Anónimo, 1910:66). Para el tercer Salón de Otoño de 1922 fue propuesto como socio (Anónimo, 1922:13). Concurrió a la Exposición Nacional de 1926 con Retrato, bronce, 0,65 x 0,40 y Retrato, bronce, 0,53 x 0,15 (Anónimo,1926:14).

13 La preeminencia de ambos personajes fue registrada en un cuadro histórico, realizado por Daniel Hernández, Saludo al presidente Leguía (1921) donde se ve al héroe francés saludando al presidente peruano frente a las delegaciones extranjeras. Destaca la figura de Andrés Avelino Cáceres, colocado en el mismo plano que los personajes centrales pero, a diferencia de ellos, mirando al espectador. 
entredicho en un estado de precaria estabilidad que recordaba a los tiempos del caudillaje de los inicios de la República.

Leguía supo explotar bien el incidente ocurrido el 28 de mayo de 1909, cuando un grupo del partido demócrata, dirigido por Carlos, Isaías y Amadeo de Piérola, lo sacó del Palacio de Gobierno en calidad de prisionero y lo llevó a la Plaza del Congreso para exigirle su renuncia. A pesar de correr el riesgo de perder la vida, Leguía no firmó (Basadre, 2005:214) ${ }^{14}$. Este hecho, conocido como el Día del Carácter, sería celebrado ampliamente durante el oncenio. Esto, unido a la personalidad autoritaria y protagónica del presidente, hizo que su figura fuera incorporada en la celebración del Centenario. No sorprende que fuera el primer presidente vivo con una avenida que llevara su nombre. Esta principal arteria unía el balneario de Miraflores con el centro de la capital, su busto estaba colocado estratégicamente al inicio. Realizar una escultura al presidente o perennizarlo a través de un lienzo fue algo usual para los artistas que querían integrarse en un mercado artístico recién formado, que tuvieron que tratar con un régimen autoritario. Leguía era un visitante habitual de las exposiciones que se celebraron en la época. Se puede decir que la presencia del régimen en el medio artístico fue una marca distintiva de este Gobierno y una manera de adquirir prestigio social.

Uno de los artistas que se convirtió, tal vez sin proponérselo, en el legitimador del Gobierno de Leguía fue el pintor peruano Daniel Hernández, que se había formado en Italia y Francia. Aunque tenía una posición incómoda, pues había sido pensionado para estudiar en Europa en el primer gobierno de José Pardo, cuyo segundo período había sido depuesto por Leguía. Además hay que agregar que fue Pardo quién había solicitado el regreso del artista para dirigir la Escuela de Bellas Artes. Para conservar su cargo, Hernández se convirtió en el pintor de historia que los Centenarios demandaban y en el principal retratista del dictador Leguía ${ }^{15}$. De hecho, resultaba extraño que el autor de escenas de género, desnudos femeninos y las famosas perezosas, tratara ahora temas tan diversos. Aquellas obras habían consagrado al artista haciéndole ganar medallas en los salones parisinos, consiguiendo incluso que lo declararan fuera de concurso. Pero los años de fama estaban lejos, él mismo reconoció su desorientación al encontrarse en París con Teófilo Castillo en 1910, cuando se refirió a las nuevas tendencias del arte dijo: "No veo sino absurdos y clichés" ${ }^{16}$. Por necesidad, Hernández se convirtió con el paso de los años en el legitimador gráfico de la política publicitaria emprendida por Augusto B. Leguía.

La apropiación de la imagen de San Martín por parte de Augusto B. Leguía se hizo evidente en su reivindicación del concepto del héroe: el Día del Carácter sacó a relucir su personalidad, pues, aunque arriesgaba la vida, no claudicó

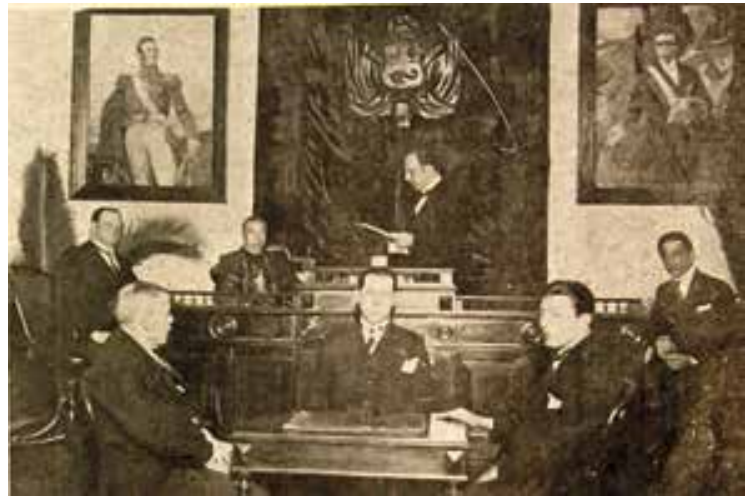

Fig.10: Consejo Municipal de Lima. Ceremonia de recibimiento del Cardenal Benlloch. Obsérvese las pinturas realizadas por Daniel Hernández. Variedades, Lima, № 821, 24 XI 1923.

14 Uno de los cuadros que directamente recogen el acontecimiento fue el realizado por Daniel Hernández, iY no firmo!

15 Hernández realizaría dos retratos a Leguía, en uno lo representa como orador (c.1923) y en otro sentado (c.1926). Ambos fueron portada en Mundial. Además de ellos, el pintor lo representó en dos cuadros más: iY no firmo! (c.1928) que también fue portada en la misma revista y en Saludo al presidente Leguía (1921). Resaltamos el hecho que fueron portada para corroborar la relación de Hernández con Leguía.

16 Castillo, 1915: p.2288. 


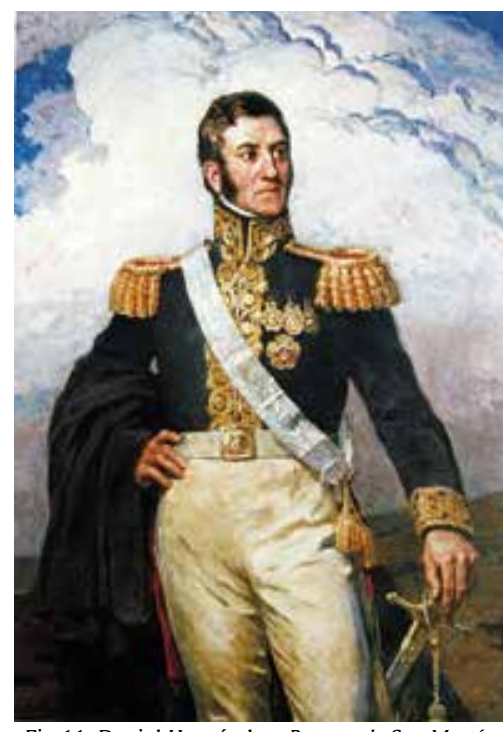

Fig.11: Daniel Hernández. Retrato de San Martín (c.1923), óleo sobre lienzo, 1,50 x 1,08 cm, Pinacoteca Municipal Ignacio Merino

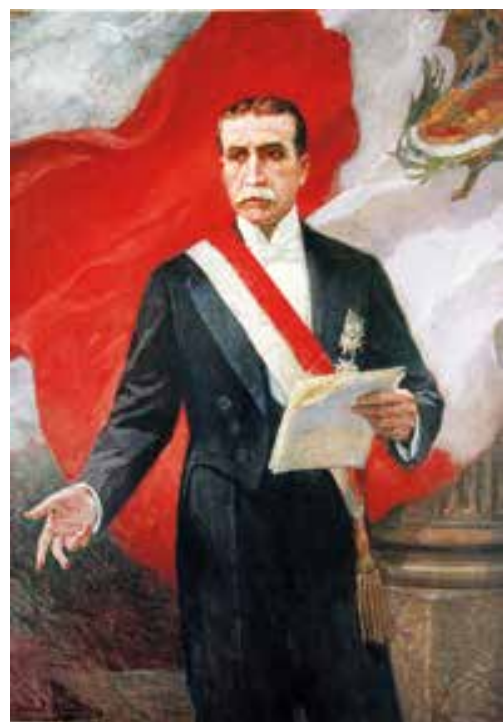

Fig.12: Daniel Hernández. Retrato de Augusto $B$. Leguía (c.1923), óleo sobre lienzo, 1,49 x 1,07 $\mathrm{cm}$, Pinacoteca Municipal Ignacio Merino frente a sus enemigos. Sus partidarios políticos comentaban sus cualidades sobresalientes, aquellas recogidas entre los visitantes a las celebraciones del Centenario y publicadas en Mundial. Los funcionarios de gobierno, tenían en sus dependencias su fotografía en la parte central de su despacho y el propio presidente asistía a todo evento cultural y social de entonces.

La personalización de su imagen, identificada con el aura del héroe, culminó en la asociación de su figura con la de San Martín. En el Consejo Provincial de Lima, colgaban simultáneamente dos cuadros (Fig.10) pintados por Daniel Hernández: el primero, era el Retrato de José de San Martín (Fig.11) en el que había retomado el modelo pintado en 1919, pero desprovisto de sombrero y capa, con un paisaje difuso de nubes. El segundo, era el Retrato de Augusto B. Leguía (Fig.12), con la bandera de fondo y en actitud de orador. La analogía entre ambos retratos se revelaba en la posición de los cuerpos y las miradas en forma dialogante. San Martín en actitud quieta mira al orador Leguía, quién muestra movimiento al sostener el documento del discurso y mover la mano derecha. El primero, contempla al segundo quien se encarga de pronunciar el discurso. Además, para enfatizar esta conexión, Hernández los representó de dos tercios. Así, podemos comprobar cómo Leguía se apropió de una de las características de San Martín: haber anunciado la independencia peruana. La actitud declamatoria fue mayoritariamente un elemento distintivo del héroe argentino, presente en varias de sus representaciones plásticas y escultóricas. Además, se encontraba en un entorno indefinido en medio de los Andes, mientras que el presidente orador iba acompañado por la bandera peruana.

La asociación de la patria nueva con la imagen del prócer, se consumó en su representación como fundador de un nuevo orden. Esto se evidenció en una estampilla realizada en el Centenario, donde estaban juntos los Retratos de San Martín y Leguía. En la parte posterior se colocó la imagen de La proclamación de la independencia de Juan Oswaldo Lepiani. Pero quizá esta suplantación en el imaginario artístico local fue evidente en el diploma hecho por el pintor Altissimo, como homenaje al presidente por haber realizado las fiestas del Centenario. En dicho documento, el pintor escenificó en acuarela, a la patria sentada y a San Martín pasándole el testigo al presidente Leguía al entregarle la bandera nacional. Esta apropiación de la imagen de San Martín, por el oncenio de Leguía, prueba cómo la imagen visual puede asumir repertorios políticos, incluso personalizados en un sólo individuo. 


\section{Referencias bibliográficas}

Anónimo

1901a "El escultor Lorenzo Roselló". El Comercio, Lima, diciembre 9, p.5.

1901b "Monumento a San Martín". El Comercio, Lima, junio 5, p.1.

1901c Catálogo de la Exposición Nacional de Bellas Artes de 1901. Madrid, Casa Editorial Mateu (MNCARS).

1906 El Monumento a San Martín reunión en Actualidades". Actualidades, №163, Lima, mayo 12.

1908 Catálogo oficial de la Exposición Nacional de Pintura, Escultura y Arquitectura de 1908. Madrid, Artes Gráficas Mateu (MNCARS).

1910 Catálogo oficial de la Exposición Nacional de Pintura, Escultura y Arquitectura de 1910. Madrid, Artes Gráficas Mateu (MNCARS).

1922 "El tercer Salón de Otoño". $A B C$, Madrid, noviembre 1, p.13.

1926a "Inauguración del Monumento a San Martín en Barranco".Variedades, Nº935, Lima, enero 30.

1926b Catálogo oficial de la Exposición Nacional de Bellas Artes de 1926. Madrid, Artes Gráficas Mateu (MNCARS).

Basadre, Jorge

1968 Historia de la república del Perú, 18221933, Lima, Editorial Universitaria. T.11, $12,13$.

2005 Historia de la república del Perú, 18221933, Lima, Empresa Editora El Comercio S.A., T. 12.

Castillo, Teófilo

1915 "Interiores limeños XIV Casa de la Sucesión del Dr. Pablo Olaechea y Casa del Doctor Manuel Augusto Olaechea". En: Variedades, №382, Lima, junio 26, pp.2283-2288.

Cisneros, Benjamín B.

1921 "San Martín” Mundial, No Extraordinario, Lima, julio 28.

Ego

1929 "Como se honra en el Perú la memoria del protector", Variedades, $\mathrm{N}^{\circ} 1116$, Lima, julio 26.

\section{El Corresponsal}

1916 "El Monumento a San Martín en Lima. Los grandes proyectos de urbanización de la ciudad", La Nación, Buenos Aires, abril 29.
De la Colina, José

1916a Carta dirigida al señor oficial mayor del Ministerio de Relaciones Exteriores del Perú, junio 14, Barcelona (AMREP).

1916b Carta dirigida al señor oficial mayor del Ministerio de Relaciones Exteriores del Perú, julio 14, Barcelona (AMREP).

1916c Carta dirigida al señor oficial mayor del Ministerio de Relaciones Exteriores del Perú, septiembre 17, Barcelona (AMREP).

\section{Gamarra, José Antonio}

1996 Obras de arte y turismo Monumental bronces, ecuestres, estatuas (de pie y sentadas), bustos, obeliscos..., Lima: Imprenta K.U.E.I.R.L.

Larrañaga, Federico

1906a "Concurso del Monumento á San Martín el proyecto de Carlos Baca Flor", Actualidades, $\mathrm{N}^{\circ} 162$, Lima, mayo 5, pp.443-445.

1906b "Un monumento a San Martín", Actualidades, $\mathrm{N}^{\circ} 194$, Lima, diciembre 15 , pp.1337-1338.

Macera, Pablo

1971 "Discusión La Independencia”, Caretas, Lima, No ${ }^{\circ} 39$, julio 16-23, pp.13-20.

Mejía, Víctor

2013 Prefiguración de la Plaza San Martín y su monumento (1899-1921), Lima, Pontificia Universidad Católica del Perú, Tesis Maestría en Historia del Arte.

Monteverde, Luis

2014 Proyectos estatales y privados para erigir un monumento público al general José de San Martín en Lima y Callao (1822-1921), Lima, Universidad Nacional Mayor de San Marcos, Tesis Licenciatura en Arte.

\section{Portocarrero, Gonzalo}

2015 "Pancho Fierro y la crítica al colonialismo como condición del surgimiento del proyecto criollo". En La urgencia por decir nosotros. Los intelectuales y la idea del Perú Republicano. Lima: Fondo Editorial PUCP. pp 25-84.

Villegas, Fernando

2010 "La escultura en el 900: entre la obra europea importada y la formación de la escultura nacional", Revista del Museo Nacional, T. L, Lima, pp.211-245.

2013 Vínculos artísticos entre España y Perú (1892-1929). Elementos para la construcción del imaginario nacional peruano, Madrid, Universidad Complutense de Madrid, Tesis doctoral en Historia del Arte. 